\title{
GAMBARAN PERILAKU DAN MOTIVASI CUCI VAGINA PADA WANITA USIA SUBUR DENGAN SERVISITIS DI PUSKESMAS II DENPASAR SELATAN
}

\author{
Vaginal Douching Motivation and Behaviour in Cervicitis WUS in Public Health Care \\ South Denpasar II
}

\author{
Komang Ayu Purnama Dewi ${ }^{1}$, Ni Made Nurtini ${ }^{2}$, Ni Made Ayu Yulia Raswati Teja ${ }^{3}$ \\ ${ }^{1,2,3}$ STIKES Bali, Jalan Tukad Balian No 180 Renon Denpasar \\ Email: ayupurnama.stikesbali@gmail.com
}

\begin{abstract}
ABSTRAK
Servisitis merupakan kasus yang paling sering dijumpai di Bali dan Denpasar khususnya di Puskesmas II Denpasar Selatan. Salah satu etiologi non infeksi penyebab dari servisitis adalah perilaku cuci vagina. Cuci vagina adalah proses pembilasan atau pembersihan vagina dengan memaksa air atau cairan lain masuk ke dalam rongga vagina untuk membersihkan atau membilas keputihan dan lainnya. Peneliti tertarik mengetahui tentang gambaran dan motivasi perilaku cuci vagina pada WUS dengan servisitis di Puskesmas II Denpasar Selatan. Sampel dalam penelitian ini adalah WUS dengan servisitis yang berkunjung ke Puskesmas II Denpasar Selatan selama bulan Januari-Pebruari 2018, yaitu sebanyak 44 orang. Sebagian besar WUS dengan servisitis melakukan cuci vagina dengan menggunakan air saja yaitu 26 orang $(59.09 \%)$, melakukan cuci vagina pada saat buang air kecil yaitu sebanyak 25 orang (56.82\%), melakukan cuci vagina di rumah/tempat tinggal yaitu 38 orang $(86.36 \%)$, dan melakukan cuci vagina sendiri yaitu 36 orang $(81.82 \%)$. Sebagian besar motivasi perilaku cuci vagina pada WUS dengan servisitis karena merasa kotor yaitu sebanyak 23 orang (52.27\%). Masih ada WUS yang melakukan cuci vagina dengan air sirih, sabun mandi, dan sabun khusus untuk cuci vagina. Penggunaan cairan selain air untuk cuci vagina ini mengakibatkan terjadinya kerusakan flora normal pada vagina sehingga mempermudah bakteri yang tidak menguntungkan untuk masuk dan menyebabkan infeksi pada vagina, servisitis, atau penyakit kelamin lainnya.
\end{abstract}

Kata kunci: Servisitis, cuci vagina, WUS

\section{ABSTRACT}

Cervicitis is the most common case in Bali and Denpasar especially in Puskesmas II South Denpasar. One of the non-infectious etiology causes of cervicitis is vaginal washing behavior. Vaginal washing is the process of rinsing or vaginal cleansing by forcing water or other fluid into the vaginal cavity to cleanse or rinse whitish and others. Researchers are interested to know about the description and motivation of vaginal washing behavior on WUS with cervicitis in Puskesmas II South Denpasar. Samples of this study were WUS with cervicitis visiting Puslesmas II South Denpasar during January - February 2018, as many as 44 people. Most of WUS with cervicitis do vagina washing with water only 26 people (59.09\%), washing vagina at the time of urination as many as 25 people (56.82\%), washing vagina at home / residence of 38 people $(86.36 \%)$ and washing their own vagina is 36 people $(81.82 \%)$. Most of the motivation of vaginal washing behavior on WUS with cervicitis because it felt dirty yaittu as many as 23 people (52.27\%). There are still WUS who wash the vagina with betel water, bath soap and a special soap for washing the vagina. The use of liquid other than water to wash this vagina resulted in the occurrence of damage to normal flora in the vagina that facilitate unfavorable bacteria to enter and cause infection in the vagina, cervicitis or other genital diseases.

Keywords: Cervicitis, douching vagina, WUS 
Purnama Dewi : Gambaran Perilaku dan Motivasi Cuci Vagina Pada WUS dengan Servisitis di Puskesmas II Denpasar Selatan

\section{Pendahuluan}

Servisitis merupakan infeksi yang terjadi pada serviks uteri. Serviks uteri yang terinfeksi akan memudahkan terjadinya infeksi pada organ reproduksi wanita yang lebih dalam seperti uterus, tuba ovari bahkan ovarium. Penyebab dari servisitis adalah infeksi menular seksual (IMS), seperti pendapat Prawirohardjo (2010) bahwa pada beberapa penyakit kelamin, seperti gonore, sifilis, ulkus mole, dan granuloma inguinal, serta pada tuberkulosis ditemukan radang pada serviks.

Selain etiologi infeksi penyebab dari servisitis, salah satu etiologi non infeksi penyebab dari servisitis adalah perilaku cuci vagina. Azizah (2011) mengatakan bahwa ada hubungan antara pemakaian vaginal douching dengan kejadian servisitis. Khasanah (2014) juga menyatakan ada hubungan yang bermakna antara perilaku cuci vagina dengan terhadap kejadian servisitis, karena cuci vagina dapat mengganggu flora normal pada vagina.

Cuci vagina adalah proses pembilasan atau pembersihan vagina dengan memaksa air atau cairan lain masuk ke dalam rongga vagina untuk membersihkan atau membilas keputihan dan lainnya. Cairan yang digunakan untuk membilas vagina tersedia dan dijual bebas di apotek ataupun toko obat. Cairan ini dibuat dari berbagai wewangian oleh beberapa produsen dan ada juga yang hanya dapat dibeli dengan resep untuk mengobati kondisi tertentu atau mempersiapkan diri untuk prosedur tertentu (Cornforth.T, 2009).

Berdasarkan data Dinas Kesehatan Provinsi Bali, kasus servisitis paling sering ditemui yaitu sejumlah 799 kasus. Selanjutnya, uretritis non gonore sebanyak 606 kasus, gonore sebanyak 527 kasus, kandidiasis 415 kasus, sifilis 78 kasus, trikomoniasis 17 kasus, herpes genital 5 kasus, dan ulkus mole 2 kasus (Tribun Bali, 2015). Di Klinik IMS Puskesmas II Denpasar Selatan, kasus servisitis juga merupakan kasus IMS yang tertinggi. Sridana dan Indrayani (2012) mengatakan IMS yang paling sering terjadi adalah servisitis dengan jumlah 200 kasus $(33,3 \%)$, diikuti oleh gonore sebanyak 14 kasus $(2,3 \%)$, serta sifilis dan urethritis masing-masing sebanyak 10 kasus $(1,7 \%)$.

Servisitis merupakan kasus yang paling sering dijumpai di Bali dan Denpasar khususnya di Puskesmas II Denpasar Selatan. Salah satu penyebab non infeksinya adalah perilaku cuci vagina. Berdasarkan uraian di atas maka peneliti tertarik mengetahui tentang gambaran dan motivasi perilaku cuci vagina pada WUS dengan servisitis di Puskesmas II Denpasar Selatan.

\section{Tujuan}

Untuk mengetahui gambaran karakteristik dan motivasi cuci vagina pada WUS dengan servisitis.

\section{Metode}

Penelitian ini merupakan penelitian deskriptif kuantitatif dengan rancangan cross sectional untuk mengetahui gambaran dan motivasi perilaku cuci vagina pada WUS dengan servisitis di Puskesmas II Denpasar Selatan. Populasi pada penelitian ini adalah seluruh WUS dengan servisitis di Puskesmas II Denpasar Selatan. Sampel pada penelitian ini adalah WUS dengan servisitis yang berkunjung ke Puskesmas II Denpasar Selatan selama bulan JanuariPebruari 2018, yaitu sebanyak 44 orang WUS. Teknik pengambilan sampel adalah consecutive sampling. Pengumpulan data dalam penelitian ini mempergunakan kuesioner, yaitu kuesioner tentang gambaran dan motivasi perilaku cuci vagina pada WUS dengan servisitis. Calon responden diberikan penjelasan tentang maksud dan tujuan dilakukannya penelitian. Selanjutnya peneliti menyerahkan surat permohonan menjadi responden. Calon responden baru bisa mengisi kuesioner setelah menandatangani surat persetujuan menjadi responden (informed consent). Analisis data yang digunakan dalam penelitian ini adalah analisis univariat. Dalam analisis ini, variabel disusun secara deskriptif untuk 
Purnama Dewi : Gambaran Perilaku dan Motivasi Cuci Vagina Pada WUS dengan Servisitis di Puskesmas II Denpasar Selatan

menggambarkan karakteristik masingmasing melalui tabel frekuensi.

Hasil

Gambaran Karasteristik Responden

Tabel 1. Karasteristik Responden Berdasarkan Umur, Pendidikan dan Pekerjaan

\begin{tabular}{|c|c|c|}
\hline Karakteristik & $\mathbf{F}$ & $\%$ \\
\hline \multicolumn{3}{|l|}{ Umur (th): } \\
\hline 24 & 4 & 9.09 \\
\hline 35 & 10 & 22.73 \\
\hline 36 & 5 & 11.36 \\
\hline 38 & 5 & 11.36 \\
\hline 39 & 2 & 4.55 \\
\hline 40 & 3 & 6.82 \\
\hline 44 & 3 & 6.82 \\
\hline 45 & 3 & 6.82 \\
\hline 46 & 3 & 6.82 \\
\hline 48 & 2 & 4.55 \\
\hline 49 & 2 & 4.55 \\
\hline 56 & 2 & 4.55 \\
\hline \multicolumn{3}{|l|}{ Pendidikan: } \\
\hline SD & 13 & 29.55 \\
\hline SMP & 5 & 11.36 \\
\hline SMA & 22 & 50.00 \\
\hline D3 & 2 & 4.55 \\
\hline Tidak sekolah & 2 & 4.55 \\
\hline \multicolumn{3}{|l|}{ Pekerjaan: } \\
\hline Pedagang & 6 & 13.64 \\
\hline Swasta & 30 & 68.18 \\
\hline IRT & 4 & 9.09 \\
\hline Pekerja Seks & 2 & 4.55 \\
\hline Penjahit & 2 & 4.55 \\
\hline
\end{tabular}

Berdasarkan tabel di atas sebagian besar responden berumur 35 tahun yaitu sebanyak 10 orang $(22.73 \%)$, sebagian besar berpendidikan SMA yaitu sebanyak 22 orang (50.00\%), dan sebagian besar bekerja sebagai pegawai swasta yaitu sebanyak 30 orang (68.18\%).

Gambaran Perilaku Cuci Vagina Pada WUS Dengan Servisitis

Tabel 2. Perilaku Cuci Vagina Berdasarkan yang Digunakan untuk Cuci Vagina pada WUS dengan Servisitis

\begin{tabular}{lcc}
\hline \multirow{2}{*}{ Jawaban } & \multicolumn{2}{c}{$\begin{array}{c}\text { Yang digunakan } \\
\text { untuk melakukan } \\
\text { Cuci Vagina }\end{array}$} \\
\cline { 2 - 3 } & F & \% \\
\hline Air saja & 26 & 59.09 \\
Air sirih & 5 & 11.36 \\
Sabun mandi & 8 & 18.18 \\
Sabun khusus cuci vagina & 5 & 11.36 \\
\hline Total & $\mathbf{4 4}$ & $\mathbf{1 0 0}$ \\
\hline
\end{tabular}

Berdasarkan tabel 2 sebagian besar WUS dengan servisitis melakukan cuci vagina dengan menggunakan air saja yaitu 26 orang $(59.09 \%)$, dengan air sirih sebanyak 5 orang $(11.36 \%)$, dengan sabun mandi sebanyak 8 orang $(18.18 \%)$, dan dengan sabun khusus untuk cuci vagina sebanyak 5 orang $(11.36 \%)$.

Tabel 3. Perilaku Cuci Vagina Berdasarkan Kapan Biasanya WUS dengan Servisitis Melakukan Cuci Vagina

\begin{tabular}{lcc}
\hline \multirow{2}{*}{ Jawaban } & $\begin{array}{c}\text { Kapan biasanya } \\
\text { melakukan cuci } \\
\text { vagina }\end{array}$ \\
\cline { 2 - 3 } & $\mathbf{F}$ & $\mathbf{\%}$ \\
\hline Saat mandi & 6 & 13.64 \\
Setelah buang air kecil & 25 & 56.82 \\
Setelah berhubungan & 13 & 29.55 \\
Pada waktu tertentu & 0 & 0 \\
\hline Total & $\mathbf{4 4}$ & $\mathbf{1 0 0}$ \\
\hline
\end{tabular}

Berdasarkan table 3 sebagian besar WUS dengan servisitis melakukan cuci vagina pada saat buang air kecil yaitu sebanyak 25 orang $(56.82 \%), 13$ orang $(29.55 \%)$ melakukan cuci vagina setelah berhubungan, dan 6 orang (13.64\%) melakukan cuci vagina pada saat mandi.

Tabel 4. Perilaku Cuci Vagina Berdasarkan Dimana WUS dengan Servisitis Melakukan Cuci Vagina

\begin{tabular}{lcc}
\hline \multirow{2}{*}{\multicolumn{1}{c}{ Jawaban }} & \multicolumn{2}{c}{$\begin{array}{c}\text { Dimana melakukan } \\
\text { cuci vagina }\end{array}$} \\
\cline { 2 - 3 } & $\mathbf{F}$ & $\mathbf{\%}$ \\
\hline Rumah/tempat tinggal & 38 & 86.36 \\
Klinik kesehatan & 0 & 0 \\
Salon kecantikan/SPA & 6 & 13.64 \\
Di mana saja & 0 & 0 \\
\hline Total & $\mathbf{4 4}$ & $\mathbf{1 0 0}$
\end{tabular}

Berdasarkan tabel 4 sebagian besar WUS dengan servisitis melakukan cuci vagina di rumah/tempat tinggal yaitu 38 orang $(86.36 \%)$, dan 6 orang (13.64\%) melakukan cuci vagina di salon kecantikan/SPA. 
Purnama Dewi : Gambaran Perilaku dan Motivasi Cuci Vagina Pada WUS dengan Servisitis di Puskesmas II Denpasar Selatan

Tabel 5. Perilaku Cuci Vagina Berdasarkan Siapa yang Membantu WUS dengan Servisitis Melakukan Cuci Vagina

\begin{tabular}{lcc}
\hline \multirow{2}{*}{ Jawaban } & \multicolumn{2}{c}{$\begin{array}{c}\text { Siapa yang membantu } \\
\text { melakukan cuci vagina }\end{array}$} \\
\cline { 2 - 3 } & $\mathbf{F}$ & $\mathbf{\%}$ \\
\hline Diri sendiri & 36 & 81.83 \\
Teman & 2 & 4.55 \\
Tenaga medis & 0 & 0 \\
Terapis & 6 & 13.64 \\
\hline Total & $\mathbf{4 4}$ & $\mathbf{1 0 0}$ \\
\hline Berdasarkan tabel & 5 & sebagian besar WUS \\
dengan servisitis & melakukan cuci vagina \\
sendiri yaitu 36 orang (81.82\%), 2 orang \\
(4.55\%) dibantu oleh teman, dan 6 orang \\
(13.64\%) melakukan cuci vagina dibantu \\
oleh therapis.
\end{tabular}

\section{Motivasi Perilaku Cuci Vagina Pada WUS Dengan Servisitis}

Tabel 6. Motivasi Perilaku Cuci Vagina pada WUS dengan Servisitis

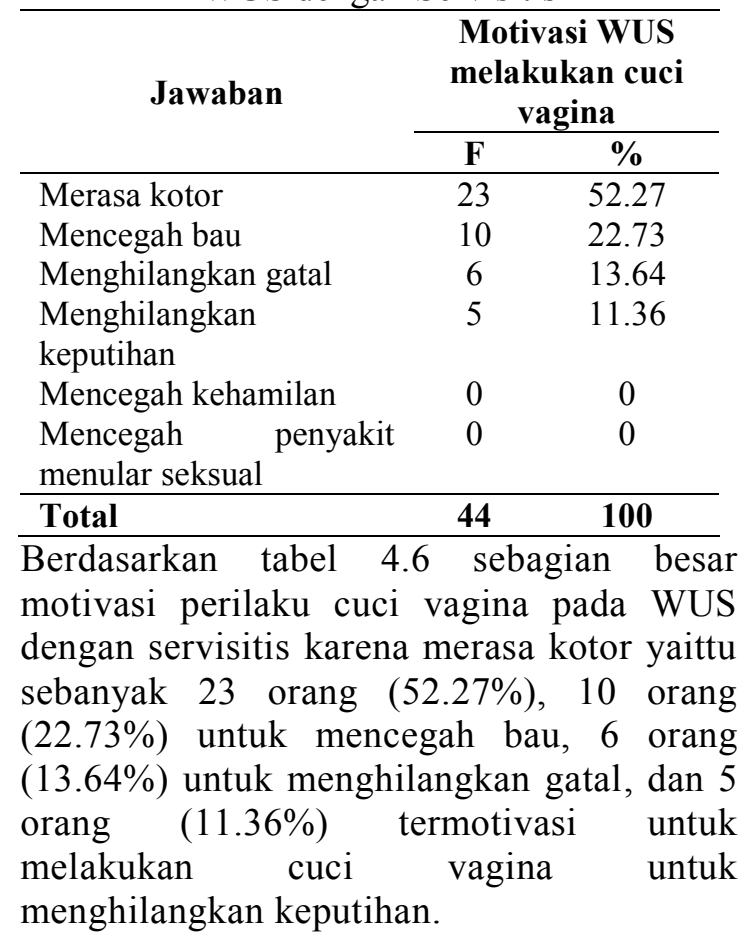

\section{Pembahasan}

Gambaran Perilaku Cuci Vagina Pada WUS Dengan Servisitis

Gambaran perilaku cuci vagina pada WUS dengan servisitis didapatkan bahwa sebagian besar WUS melakukan cuci vagina dengan menggunakan air saja. Cuci vagina yang dilakukan dengan air saja tidak akan merusak flora normal vagina, namun masih ada WUS yang melakukan cuci vagina dengan air sirih, sabun mandi dan sabun khusus untuk cuci vagina. Penggunaan cairan selain air untuk cuci vagina ini mengakibatkan terjadinya kerusakan flora normal pada vagina sehingga mempermudah bakteri yang tidak menguntungkan untuk masuk dan menyebabkan infeksi pada vagina, servisitis atau penyakit kelamin lainnya. Hal ini sesuai dengan pendapat Sten $\mathrm{H}$. Vermund, et all (2009), pencucian vagina meningkatkan risiko untuk infeksi IMS karena pada saat pencucian vagina hydrogen peroxide dalam vagina ikut terbilas. Hydrogen peroxide merupakan hasil produksi dari organisme lactobacilli, yaitu bagian dari flora normal vagina dimana organisme ini akan memproduksi asam laktat yang menjaga keasaman $\mathrm{PH}$ vagina.

Pada penelitian ini sebagian besar WUS melakukan cuci vagina sendiri yang dilakukan di rumah. Cuci vagina yang dilakukan sendiri di rumah merupakan salah satu upaya untuk menjaga kebersihan vagina yang wajib dilakukan oleh setiap wanita. Sebagian kecil terdapat WUS yang melakukan cuci vagina di salon kecantikan/SPA. Cuci vagina yang dilakukan di salon kecantikan/SPA yang dilakukan oleh terapis dan biasanya menggunakan cairan khusus selain air dan ramuan lainnya, dimana cairan selain air tersebut dapat merusak flora normal vagina. Pada penelitian ini juga diperoleh data bahwa WUS melakukan cuci vagina pada saat mandi, setelah buang air kecil dan setelah berhubungan.

\section{Motivasi Perilaku Cuci Vagina pada WUS Dengan Servisitis}

Motivasi perilaku cuci vagina pada WUS dengan servisitis pada penelitian ini didapatkan sebagian besar WUS melakukan cuci vagina karena merasa kotor, kemudian mencegah bau, menghilangkan gatal, dan menghilangkan keputihan. Motivasi yang mendorong WUS untuk melakukan cuci 
Purnama Dewi : Gambaran Perilaku dan Motivasi Cuci Vagina Pada WUS dengan Servisitis di Puskesmas II Denpasar Selatan

vagina sesuai dengan pendapat Vermund.SH et all (2009) yang mengatakan bahwa motivasi yang mendorong cuci vagina antara lain adalah pencegahan bau/odor, pencegahan kehamilan, pencegahan penyakit menular seksual dan infeksi genital lainnya.

\section{Kesimpulan}

Sebagian besar WUS dengan servisitis melakukan cuci vagina dengan menggunakan air saja yaitu 26 orang (59.09\%), melakukan cuci vagina pada saat buang air kecil yaitu sebanyak 25 orang (56.82\%), melakukan cuci vagina di rumah/tempat tinggal yaitu 38 orang (86.36\%), dan melakukan cuci vagina sendiri yaitu 36 orang $(81.82 \%)$. Sebagian besar motivasi perilaku cuci vagina pada WUS dengan servisitis karena merasa kotor yaitu sebanyak 23 orang (52.27\%).

\section{Daftar Pustaka}

Azizah. 2011. Hubungan Pemakaian Vaginal Douching Dengan Kejadian Servisitis Di Poli Kandungan Rsud Kelas $B$ Dr $R$ Sosodoro Djatikoesoemo Bojonegoro Tahun 2011. Skripsi thesis, Universitas Airlangga.

Cornforth, T. 2009. Vaginal Douching -To Douche or Not to Douche-The Douche Debate Continue.s. (online). (http://womenshealth.about.com/cs/azhealt htopics/a/vagdouching.html, diakses tanggal 3 Oktober 2017)

Khasanah, U. 2014. Faktor-faktor Yang Berpengaruh Terhadap Servisitis Pada Wanita Pekerja Seksual Langsung di Lokalisasi Gondanglegi. (online: diakses tanggal 2 Oktober 2017)

Prawirihardjo, S. 2012. Ilmu Kebidanan. Jakarta : yayasan Bina Pustaka Sarwono Prawirohardjo

Sridana da Indrayani. 2012. Karakteristik Pasien Infeksi Menular Seksual (IMS) Pada Puskesmas II Denpasar Selatan. Universitas Udayana

TribunBali.com ( Selasa, 7 Juli 2015) online diakses tanggal 3 oktober 2017
Vermund.SH, et all. 2009. Risk Factor for Sexually Transmitted Infections. The Female Patient vol 34 july 2009. (online) (http://www.jfponline.com/fileadmin/qhi_a rchive/ArticlePDF/TFP/034070037.pdf, diakses tanggal 2 Oktober 2017) 